\title{
HIV Surveillance: Life Skills Education Programme among in-school Adolescents
}

\author{
Olubunmi Adeyemi*1, Olufunmilayo Fawole ${ }^{2}$ and Adedayo Adeyemi ${ }^{3}$
}

${ }^{1}$ Public Health Department, Abuja, Nigeria; ${ }^{2}$ Department of Epidemiology and Medical Statistics, College of Medicine, Ibadan, Nigeria; ${ }^{3}$ Measure/National Agency for the Control of AIDS, Abuja, Nigeria

\section{Objective}

To assess the predictors of life-skills-based HIV/AIDS education on sexual behaviour among secondary school students in South West, Nigeria.

\section{Introduction}

Reduction in HIV transmission needs continuous, comprehensive and effective communication channels to disseminate messages that will sustain efforts to motivate adolescents to engage in a range of options to reduce the risk of HIV infection. Life skills education, an integral part of school-based AIDS programs that include sexual and reproductive health information, has been a timely prevention effort in schools. ${ }^{1}$ This has proven to be an effective method in delaying the onset of sexual intercourse, and among sexually experienced youth, in increasing the use of condoms and decreasing the number of sexual partners. Life skills are behaviors that enable individuals to adapt to and deal effectively with the demands and challenges of life. The life skills approach is an interactive, educational methodology that not only focuses on transmitting knowledge but also aims at shaping attitudes and developing interpersonal skills. The main goal of the life skills approach is to enhance young people's ability to take responsibility for making healthier choices, resisting negative pressures, and avoiding risk behaviors. Limited studies have been done on assessing life skills of adolescents in schools. Findings from this study will provide baseline for programmatic scale up.

\section{Methods}

A cross-sectional study design was used. A multi-stage sampling technique was used to select eight schools from four Local Government Areas (LGAs) within Ibadan Metropolis, Nigeria. Knowledge of life-skills in HIV prevention and associated factors were assessed. Univariate analysis was done to generate proportions, tables and charts; bivariate was done with Mann-Whitney U test, and multivariate analysis was done with multiple linear regressions after transformation.

\section{Results}

A total of 1467 students were selected with a mean age of $14.2 \pm 1.7$ years. About half of the respondents were females $(51.4 \%)$ and Christians (52.6\%). Majority were in senior secondary class (66.3\%), mostly from monogamous family $(75.3 \%)$ and living with both parents (77.9\%). About $14.1 \%$ of the total population had been exposed to sexual intercourse. The mean age at initiation was $15.2 \pm 1.9$ years. Only about a quarter of the respondents in both groups rated their risk of having HIV/AIDS to be high. Most agreed that adolescents/ young people need life skills (69.3\%), and the reason commonly stated was to enable them to know what is right. About half (50.3\%) said they have heard about life building skills and the commonest source of information was from school $(72.1 \%)$. The three most commonly identified life skills were communication (37.5\%), decision making $(32.4 \%)$, and goal setting (29.2\%). Low proportion of respondents poorly demonstrated negotiation and communication components of life skills. The life skills improve with exposure to family life and
HIV/AIDS education (B coefficient $=26.28, \mathrm{p}<0.001$ ); increasing age $(\mathrm{B}=2.97, \mathrm{p}=0.03)$; living in a monogamous family $(\mathrm{B}=11.45, \mathrm{p}=0.03)$; having more than one sibling $(\mathrm{B}=29.54, \mathrm{p}=0.03)$; having a trading mother $(\mathrm{B}=23.01, \mathrm{p}=0.02)$; and having an artisan mother $(\mathrm{B}=25.47$, $\mathrm{p}=0.03)$. However, living with either of the parents/guardian $(\mathrm{B}=-$ 29.71, $\mathrm{p}=0.001)$ and being in urban schools $(\mathrm{B}=-19.86, \mathrm{p}<0.001)$ significantly decreases life skills ability of the respondents.

\section{Conclusions}

This study has shown that family life and HIV/AIDS education with some socio demographic factors might have contributed to the improvement of life skills education program. Efforts should be made to sustain the effectiveness of school based education programs especially in urban areas. ${ }^{2}$

\section{Keywords}

HIV Surveillance; Life Skills; in-school Adolescents

\section{References}

1) Liao W, Jiang J, Yang B, Zeng X, Liao S. A Life-skills-based HIV/ AIDS prevention education for rural students of primary schools in China: What changed? What have we learned? Biomedical and Environmental Sciences. 2010;23:409-19.

2) Fawole IO, Asuzu MC, Oduntan SO, Brieger WR. A school-based AIDS education programme for secondary school students in Nigeria: a review of effectiveness. Health Education Research. 1999;14 (5):675-83.

*Olubunmi Adeyemi

E-mail: bumfaks2002@yahoo.ca 